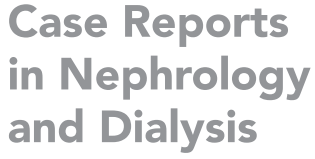

Case Reports and Dialysis

Case Rep Nephrol Dial 2021:11:254-260

\title{
Diuretic Resistance Treated with Low-Dose Hydralazine: A Case Report and Review of the Literature
}

\author{
Mohammed Alshehria, b Christopher Wilcox ${ }^{a}$ \\ aDivision of Nephrology and Hypertension Center, Georgetown University, Washington, DC, \\ USA; 'bivision of Nephrology and Hypertension, Georgetown University, Washington, DC, \\ USA
}

\section{Keywords}

Furosemide $\cdot$ Chlorothiazide $\cdot$ Heart failure with preserved ejection fraction · Cardiorenal syndrome

\begin{abstract}
We present a case of severe diuretic resistance and edema from acute cardiorenal syndrome complicating heart failure with preserved ejection fraction (HFpEF) and mild alcoholic liver disease. High doses of intravenous (iv) furosemide plus iv doses of chlorothiazide failed to increase the daily urine output (UV) above $1,500 \mathrm{~mL}$ or the fractional excretion of sodium $\left(\mathrm{FE}_{\mathrm{Na}}\right.$ ) above $2 \%$. The addition of a relatively low dose of hydralazine (10 mg thrice daily $\mathrm{PO}$ ) during 5 days of constant iv infusion of furosemide plus iv bolus chlorothiazide doubled the UV and $\mathrm{FE}_{\mathrm{Na}}$ while reducing the serum creatinine concentration from 3.3 to $2.0 \mathrm{mg} / \mathrm{dL}$. Hydralazine may have restored a response to the diuretics by increasing the renal blood flow and thereby the renal diuretic delivery, or by reducing the filtration fraction or reducing the renal congestion and thereby reducing the proximal reabsorption during blockade of distal reabsorption with diuretics. Further mechanistic studies of low-dose hydralazine for diuretic resistance are warranted.
\end{abstract}

(c) 2021 The Author(s).

Published by S. Karger AG, Basel

\section{Introduction}

Diuretic resistance is a failure to clear congestion or edema despite a full diuretic dosage. It is associated with worse short- and long-term outcomes [1]. Here, we present a case of diuretic-resistant volume overload where the addition of a low dose of hydralazine restored 
the responsiveness to diuretics and relieved the congestion. We discuss a potential role of low-dose hydralazine in diuretic-resistant heart failure, review the literature, and propose physiological mechanisms.

\section{Case Report}

The patient was a 52-year-old female with a past medical history of hypertension, obesity, heart failure with preserved ejection fraction (HFpEF), and mild alcoholic liver disease. She was admitted to the hospital with a 3-day history of altered mental status. She was afebrile. Her BP was $109 / 59 \mathrm{~mm} \mathrm{Hg}, \mathrm{O}_{2}$ saturation $98 \%$ on room air, and weight $134 \mathrm{~kg}$. Her serum creatinine concentration (Scr) had increased from 0.8 to $3.6 \mathrm{mg} / \mathrm{dL}$ over 1 month, and she had gained $30 \mathrm{~kg}$ of weight over 5 months. Other investigations included BUN $41 \mathrm{mg} / \mathrm{dL}$, serum sodium $131 \mathrm{mmol} / \mathrm{L}$, and serum potassium $6.7 \mathrm{mmol} / \mathrm{L}$. Hyperkalemia was treated successfully with iv furosemide plus insulin with glucose. She was managed initially for presumed hepatorenal syndrome (HRS) with infusions of human salt-poor albumin, midodrine, and octreotide but had no significant improvement. The nephrology team was consulted on the third hospital day.

Physical examination revealed jugular venous distention of $>5-8 \mathrm{~cm} \mathrm{H}_{2} \mathrm{O}$, decreased breath sounds at the lung bases, and 2+ pitting edema of the lower extremities up to the lower abdomen. Laboratory values included a hemoglobin of $8.7 \mathrm{~g} / \mathrm{dL}$, platelet count of 109,000/ $\mu \mathrm{L}$, serum sodium $140 \mathrm{mmol} / \mathrm{L}$, serum potassium $3.8 \mathrm{mmol} / \mathrm{L}$, serum chloride $106 \mathrm{mmol} / \mathrm{L}$, serum total $\mathrm{CO}_{2} 23 \mathrm{mmol} / \mathrm{L}$, BUN $47 \mathrm{mg} / \mathrm{dL}$, Scr $3.47 \mathrm{mg} / \mathrm{dL}$, and proBNP 1,170 pg/mL with normal values for blood glucose, calcium, and liver enzymes but a reduced plasma albumin of $2.5 \mathrm{~g} / \mathrm{dL}$. Urinalysis revealed a specific gravity of 1.017 without proteinuria or casts. Urine sodium and chloride concentrations were $<10 \mathrm{mmol} / \mathrm{L}$, and fractional excretion of $\mathrm{Na}^{+}\left(\mathrm{FE}_{\mathrm{Na}}\right)$ was $0.1 \%$. The preserved renal concentrating ability, low $\mathrm{FE}_{\mathrm{Na}}$, and absence of proteinuria or casts suggested a hemodynamic basis for her increase in Scr.

A chest X-ray revealed signs of pulmonary edema. An echocardiogram from 2 weeks prior revealed a preserved ejection fraction of $60-65 \%$ but diastolic dysfunction. Abdominal sonography was negative for ascites.

The patient was diagnosed with an exacerbation of HFpEF. Acute tubular necrosis was considered unlikely because of the absence of a specific cause for acute tubular necrosis, the urine studies, and the significant volume overload. HRS also was considered unlikely because of the lack of ascites, the failure to respond to the specific HRS therapy, and the high level of proBNP that favored the primary diagnosis of HF. Therefore, diuretic therapy was intensified to furosemide $80 \mathrm{mg}$ plus chlorothiazide $250 \mathrm{mg}$, both given iv twice daily. Her urine output (UV) increased modestly from 350 to $550 \mathrm{~mL}$, and diuretics were escalated to a continuous iv infusion of furosemide $(20 \mathrm{mg} / \mathrm{h})$ plus iv bolus doses of chlorothiazide ( 500 mg twice daily), but this failed to increase UV above $1,500 \mathrm{~mL}$ or $\mathrm{FE}_{\mathrm{Na}}$ above $2 \%$ and did not improve her symptoms or change her Scr (shown in Fig. 1). During stable diuretic therapy on hospital day 6, hydralazine (10 mg thrice daily PO) was added. Within $24 \mathrm{~h}$, her Scr began to decrease to a nadir after 5 days of $1.98 \mathrm{mg} / \mathrm{dL}$, and her $\mathrm{UV}$ and $\mathrm{FE}_{\mathrm{Na}}$ doubled. Her clinical state improved sufficiently on day 11 to begin an oral regimen of furosemide $(80 \mathrm{mg}$ twice daily) plus spironolactone (200 mg daily) and hydralazine (20 mg three times daily). Over the hospital course of 19 days, the patient lost $23 \mathrm{~kg}$ in weight, and her Scr improved to $1.3 \mathrm{mg} / \mathrm{dL}$. At follow-up after 3 months while she was prescribed furosemide $80 \mathrm{mg}$ twice daily plus spironolactone $200 \mathrm{mg}$ daily, her symptoms remained well controlled, her weight was reduced by a further $10 \mathrm{~kg}$, and her Scr was at baseline at $0.9 \mathrm{mg} / \mathrm{dL}$. Her SBP remained stable at $110-120 \mathrm{~mm} \mathrm{Hg}$.

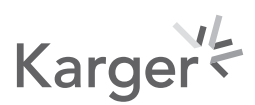




\section{DIURETIC AND NATRIURETIC RESPONSES TO HYDRALAZINE IN A PATIENT WITH RESISTANCE TO A LOOP DIURETIC + A THIAZIDE}

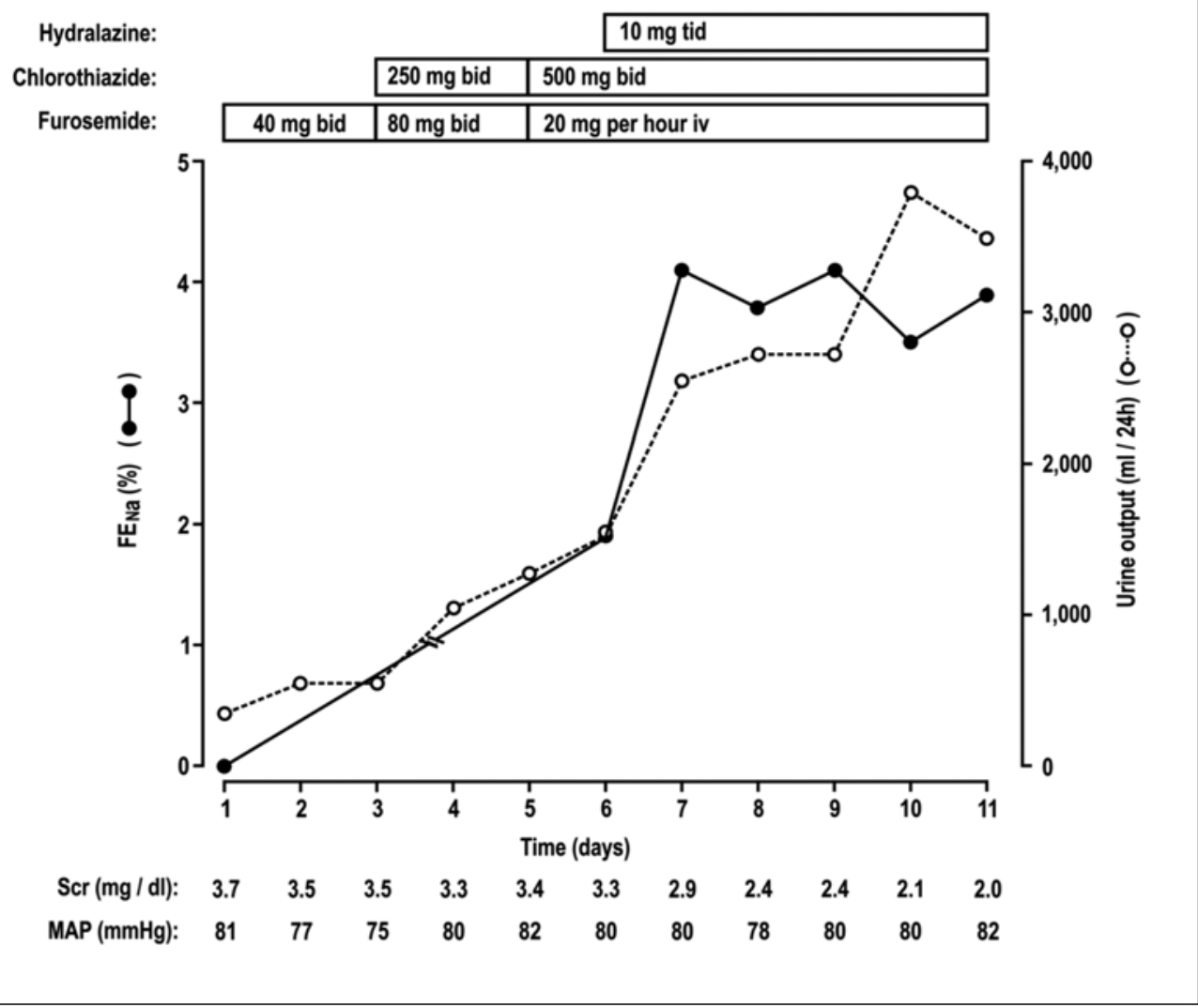

Fig. 1. Diuretic and natriuretic responses to hydralazine in a patient with resistance to a loop diuretic $+\mathrm{a}$ thiazide. Day 1 is the first day of nephrology consult. $\mathrm{FE}_{\mathrm{NA}}$, fractional excretion of sodium; Scr, serum creatinine; MAP, mean arterial pressure; bid, twice daily; tid, thrice daily.

\section{Discussion}

The renal blood flow (RBF) and the glomerular filtration rate (GFR) are reduced in many patients with congestive heart failure (CHF) and may contribute to diuretic resistance [1]. Hydralazine leads to prostaglandin-dependent renal vasodilation [2]. There are several studies of the efficacy of hydralazine in improving renal hemodynamics, UV, or sodium excretion $\left(\mathrm{U}_{\mathrm{Na}} \mathrm{V}\right)$ that are summarized in Table 1 . When measured, hydralazine has increased the RBF more than the GFR and thereby has reduced the filtration fraction (FF). It also has increased the cardiac output (CO). The increase in the RBF is likely a consequence of renal vasodilation [3], increased $\mathrm{CO}$, and decreased systemic vascular resistance. Providing that any reductions in BP are not severe, hydralazine generally has increased the $\mathrm{UV}$ and the $\mathrm{U}_{\mathrm{Na}} \mathrm{V}$.

Our patient had an increase in $\mathrm{FE}_{\mathrm{Na}}$ and diuresis with hydralazine during blockade of $\mathrm{Na}^{+}$ reabsorption in the loop of Henle and the distal tubule. This indicates that hydralazine was principally reducing reabsorption in the proximal tubule (PT). Although the reduction in Scr and the increase in the GFR with hydralazine might have contributed to $\mathrm{Na}^{+}$losses, the doubling of $\mathrm{FE}_{\mathrm{Na}}$ indicates that it had reduced tubular $\mathrm{Na}^{+}$reabsorption. 
Case Reports

in Nephrology and Dialysis
Case Rep Nephrol Dial 2021;11:254-260

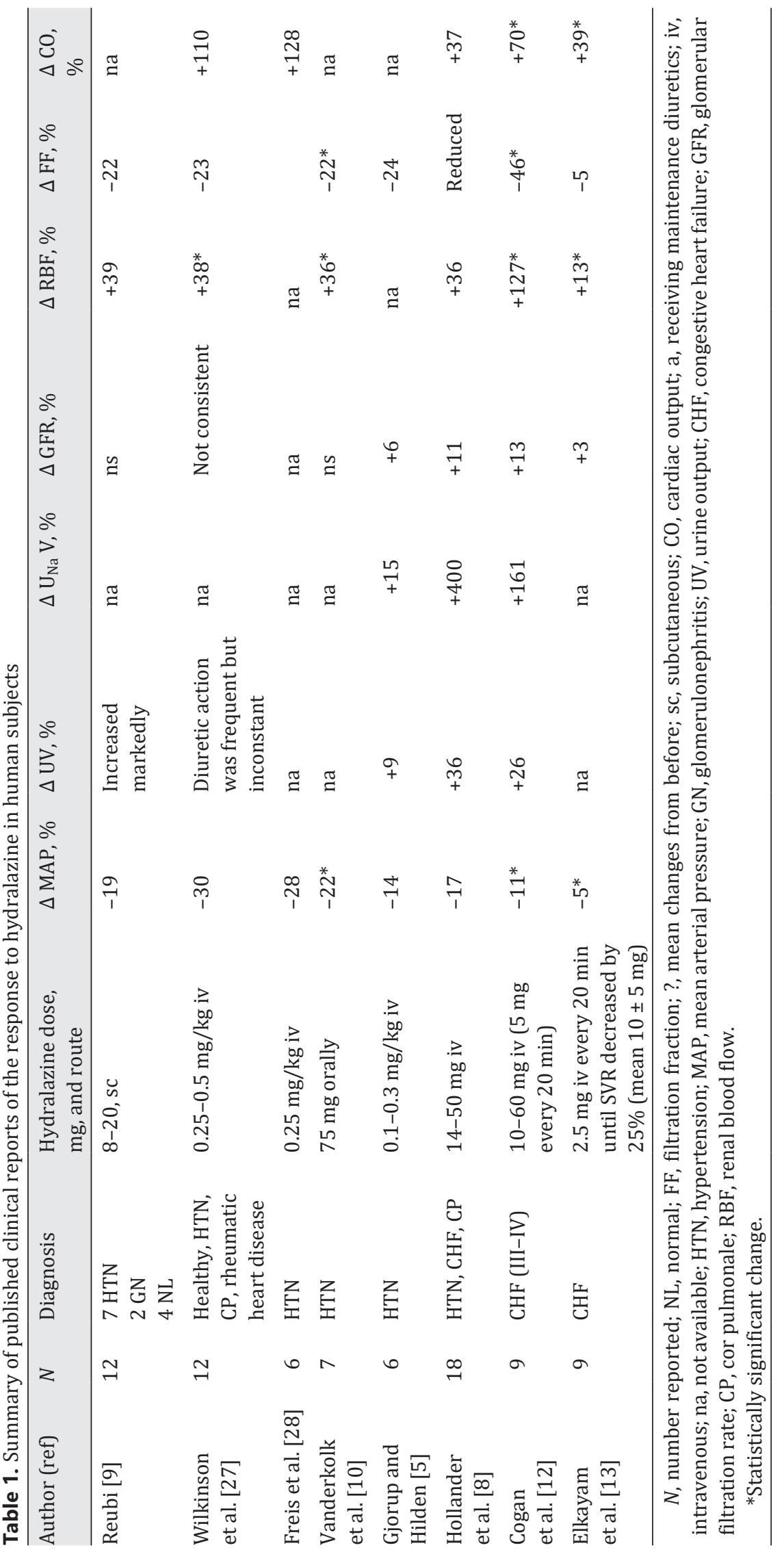




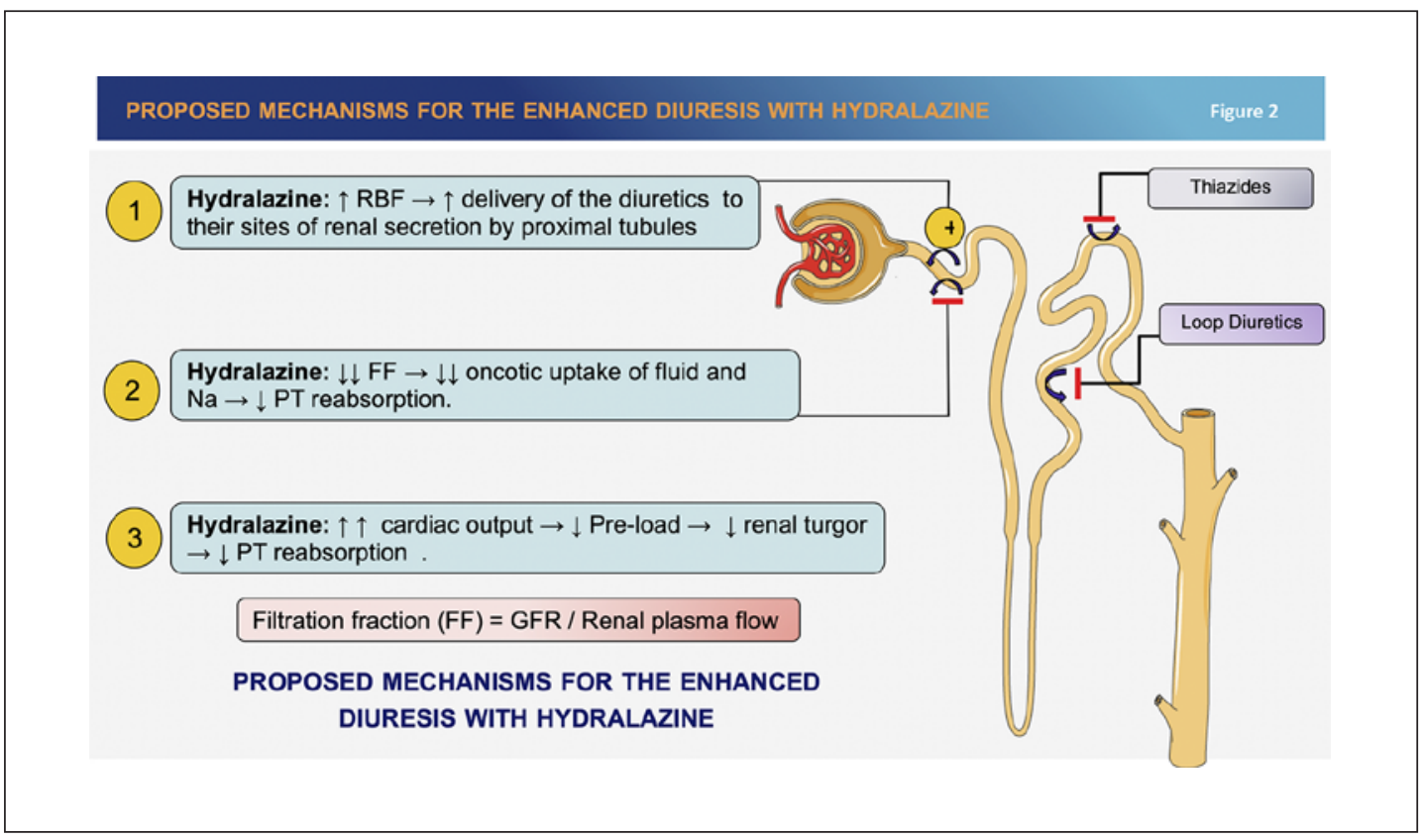

Fig. 2. Proposed mechanisms for the enhanced diuresis with hydralazine. RBF, renal blood flow; FF, filtration fraction; GFR, glomerular filtration rate.

We considered 3 mechanisms to account for the increased UV and $\mathrm{U}_{\mathrm{Na}} \mathrm{V}$ (Fig. 2). First, an increase in RBF will increase the delivery of the diuretic to the renal tubules [4, 5]. Since diuretics bind to albumin and it is required for diuretic delivery to the renal tubules, the hypoalbuminemia in our patient may have contributed to the diuretic resistance [1]. Indeed, hydralazine increases the renal clearance of furosemide [6]. However, this seems an inadequate explanation since both diuretics were being given iv at doses that are generally considered to be supramaximal [1], and an increase in diuretic dose on day 4 increased UV only marginally (Fig. 1).

Second, PT reabsorption is dependent on the oncotic pressure in the peritubular capillaries [7] that itself is dependent on the degree to which plasma water is filtered at the glomerulus that is quantitated by the FF. Hemodynamic studies with hydralazine report a consistently greater rise in RBF than in GFR, with a consequent fall in the FF [5, 8-13] (Table 1).

Third, since an increase in $\mathrm{CO}$ with hydralazine (Table 1) reduces preload, hydralazine should reduce renal venous pressure and renal congestion. Increased renal turgor in patients with CHF can contribute to increased PT reabsorption [14-16] and reduced RBF and GFR [17, 18].

Thus, hydralazine may have reduced the FF and the renal congestion and thereby reduced the PT reabsorption. Angiotensin-converting enzyme inhibitors have generally similar hemodynamic effects of increased RBF and reduced FF [19] that will increase the delivery of filtrate to the loop of Henle and distal nephron and thereby enhance diuretic responsiveness. However, many physicians are reluctant to use angiotensin-converting enzyme inhibitors in patients with an acute increase in Scr, as in this patient, but might select a renal vasodilatory drug such as hydralazine.

Hydralazine therapy requires care. Its variable and short half-life mandates 3 times daily dosing. Accurate therapy requires genotyping for $\mathrm{N}$-acetyltransferase 2 status to determine whether the patient is a slow or fast acetylator [20]. Moreover, renin increases dose dependently with hydralazine [21]. Careful monitoring of the MAP and heart rate is required, since the desired effects can be compromised by sympathetic system overactivity and activation of the renin-angiotensin-aldosterone system. 
Case Reports in Nephrology and Dialysis

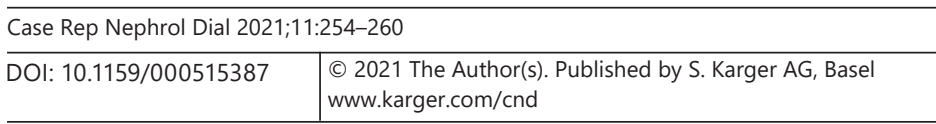

Alshehri and Wilcox: Diuretic Resistance Treated with Low-Dose Hydralazine

The MAP should not be reduced by $>25 \%$ in patients with CHF since this prevents the diuretic response [22]. Moreover, patients with HFpEF can be sensitive to blood volume depletion that requires careful use of diuretics [23]. However, the contribution of reduction in before and after load with hydralazine in patients with HFpEF should be preferable to escalating diuretic therapy since that may increase after load and thereby increase the cardiac oxygen usage [24, 25].

Although the use of vasodilator therapy to relieve systemic congestion has been reported previously, this approach has not been widely applied given the lack of a clear physiological explanation [26]. This case illustrates the potential of low-dose hydralazine to reduce reabsorption of $\mathrm{Na}^{+}$in the PT and to relieve diuretic resistance. It suggests the need for further studies to establish the mechanisms involved and the general utility.

\section{Statement of Ethics}

The authors have complied with ethical standards for this case report involving a human participant. Written informed consent for publication of this case report was obtained from the patient.

\section{Conflict of Interest Statement}

The authors have no relevant financial or nonfinancial interests to disclose.

\section{Funding Sources}

No funds, grants, or other support was received.

\section{Author Contributions}

M.A. was responsible for the patient care and wrote the initial draft. C.W. revised manuscript including the data, literature review, and results.

\section{References}

1 Wilcox CS, Testani JM, Pitt B. Pathophysiology of diuretic resistance and its implications for the management of chronic heart failure. Hypertension. 2020;76(4):1045-54.

2 Rubin LJ, Lazar JD. Influence of prostaglandin synthesis inhibitors on pulmonary vasodilatory effects of hydralazine in dogs with hypoxic pulmonary vasoconstriction. J Clin Invest. 1981;67(1):193-200.

3 Chelly JE, Doursout MF, Begaud B, Tsao CC, Hartley CJ. Effects of hydralazine on regional blood flow in conscious dogs. J Pharmacol Exp Ther. 1986;238(2):665-9.

4 Testani JM, Brisco MA, Turner JM, Spatz ES, Bellumkonda L, Parikh CR, et al. Loop diuretic efficiency: a metric of diuretic responsiveness with prognostic importance in acute decompensated heart failure. Circ Heart Fail. 2014;7(2):261-70.

5 Gjorup S, Hilden T. The effect of hydralazine (apresolin) on kidney function and sodium excretion. Scand J Clin Lab Invest. 1956;8(4):273-7.

6 Nomura A, Yasuda H, Katoh K, Akimoto T, Miyazaki K, Arita T. Hydralazine and furosemide kinetics. Clin Pharmacol Ther. 1982;32(3):303-6.

7 Brenner BM, Troy JL. Postglomerular vascular protein concentration: evidence for a causal role in governing fluid reabsorption and glomerulotublar balance by the renal proximal tubule. J Clin Invest. 1971;50(2): 336-49. 
8 Hollander W, Judson WE, Wilkins RW. The effects of intravenous apresoline (hydralazine) on cardiovascular and renal function in patients with and without congestive heart failure. Circulation. 1956;13(5):664-74.

9 Reubi FC. Renal hyperemia induced in man by a new phthalazine derivative. Proc Soc Exp Biol Med. 1950; 73(1):102.

10 Vanderkolk K, Dontas AS, Hoobler SW. Renal and hypotensive effects of acute and chronic oral treatment with 1-hydrazinophthalazine (apresoline) in hypertension. Am Heart J. 1954;48(1):95-101.

11 Moyer JH. Hydrallazine (apresoline) hydrochloride; pharmacological observations and clinical results in the therapy of hypertension. AMA Arch Intern Med. 1953;91(4):419-39.

12 Cogan JJ, Humphreys MH, Carlson CJ, Rapaport E. Renal effects of nitroprusside and hydralazine in patients with congestive heart failure. Circulation. 1980;61(2):316-23.

13 Elkayam U, Weber L, Campese VM, Massry SG, Rahimtoola SH. Renal hemodynamic effects of vasodilation with nifedipine and hydralazine in patients with heart failure. J Am Coll Cardiol. 1984;4(6):1261-7.

14 Bank N, Yarger WE, Aynedjian HS. A microperfusion study of sucrose movement across the rat proximal tubule during renal vein constriction. J Clin Invest. 1971;50(2):294-302.

15 Carlstrom M, Wilcox CS, Arendshorst WJ. Renal autoregulation in health and disease. Physiol Rev. 2015;95(2): 405-511.

16 Kaloyanides GJ, Cacciaguida RJ, Pablo NC, Porush JG. Increased sodium reabsorption in the proximal and distal tubule of caval dogs. J Clin Invest. 1969;48(8):1543-51.

17 Araujo M, Solis G, Welch WJ, Wilcox CS. Renal nerve deafferentation attenuates the fall in GFR during intravenous infusion of furosemide in anesthetized rats. Kidney Blood Press Res. 2020;45(1):70-83.

18 Mullens W, Abrahams Z, Francis GS, Sokos G, Taylor DO, Starling RC, et al. Importance of venous congestion for worsening of renal function in advanced decompensated heart failure. J Am Coll Cardiol. 2009;53(7):58996.

19 Creager M, Halperin J, Bernard D, Faxon D, Melidossian C, Gavras H, et al. Acute regional circulatory and renal hemodynamic effects of converting-enzyme inhibition in patients with congestive heart failure. Circulation. 1981;64(3):483-9.

20 Collins KS, Raviele AL, Elchynski AL, Woodcock AM, Zhao Y, Cooper-DeHoff RM, et al. Genotype-guided hydralazine therapy. Am J Nephrol. 2020;51:764-76.

21 Pettinger WA, Campbell WB, Keeton K. Adrenergic component of renin release induced by vasodilating antihypertensive drugs in the rat. Circ Res. 1973;33(1):82-6.

22 Kitai T, Tang WHW, Xanthopoulos A, Murai R, Yamane T, Kim K, et al. Impact of early treatment with intravenous vasodilators and blood pressure reduction in acute heart failure. Open Heart. 2018;5(2):e000845.

23 Mullens W, Damman K, Harjola VP, Mebazaa A, Brunner-La Rocca HP, Martens P, et al. The use of diuretics in heart failure with congestion: a position statement from the Heart Failure Association of the European Society of Cardiology. Eur J Heart Fail. 2019;21(2):137-55.

24 Palazzuoli A, Ruocco G, Ronco C, McCullough PA. Loop diuretics in acute heart failure: beyond the decongestive relief for the kidney. Crit Care. 2015;19(1):296.

25 Pfeffer MA, Shah AM, Borlaug BA. Heart failure with preserved ejection fraction in perspective. Circ Res. 2019; 124(11):1598-617.

26 Cohn JN, Mathew KJ, Franciosa JA, Snow JA. Chronic vasodilator therapy in the management of cardiogenic shock and intractable left ventricular failure. Ann Intern Med. 1974;81(6):777-80.

27 Wilkinson EL, Backman H, Hecht HH. Cardiovascular and renal adjustments to a hypotensive agent (l'hydrazinophthalazine: Ciba BA-5968: apresoline). J Clin Invest. 1952;31(10):872-9.

28 Freis ED, Rose JC, Higgins TF, Finnerty FA Jr, Kelley RT, Partenope EA. The hemodynamic effects of hypotensive drugs in man. IV. 1-hydrazinophthalazine. Circulation. 1953;8(2):199-204. 